\title{
Content Delivery Modes for Students with Visual Impairments in Integrated Schools of Nepal
}

\author{
Dhruba Prasad Niure \\ dhrubapn@gmail.com \\ Lecturer \\ Central Department of Education \\ Tribhuvan University
}

\begin{abstract}
The purpose of this study is to explore the instructional approaches that have been using by teachers working in integrated schools for years to optimize the access of visually impaired students to general education curriculum. This study was guided by constructivist paradigm followed by case study design. Altogether eleven teachers were selected from three integrated schools located in Kathmandu Valley by using purposive sampling method. Qualitative data were gathered by using semi-structured interview, classroom observation, and document analysis to get deeper understanding on the studied phenomenon. And then garnered information were edited, transcribed, coded, and thematized to draw meaningful results and conclusions. A number of instructional techniques such as providing materials into accessible format, placing students with low vision near to chalkboard, ability based grouping, pairing blind and sighted students together, etc. were applied by targeting the distinct learning needs of students with visual impairments. But most of these instructional techniques were not used on routine basis because of poorly trained teachers, limited instructional materials, and high students-teacher ratio. Therefore, proper training, sufficient instructional materials, and manageable size of the classroom should be arranged to optimize the access of visually impaired students to general education curriculum.
\end{abstract}

Key Words: Integrated schools, curriculum, content delivery modes, students with visual impairments, general education teachers, special education teachers, resource room

\section{Introduction}

All children, including those with disabilities, have equal rights to receive education in Nepal (Nepal Law Commission, 2015). Considering the constitutional provisions, Nepal Government has been providing different types of services for long time through general, special, and integrated schools by accounting the peculiar learning needs of students with disabilities, including learners with visual impairments. These days, thirty-two special schools, twenty-two integrated schools, and three-hundred-eighty resource classes have been established in Nepal to provide special educational supports to children with disabilities as per their individual needs and learning styles. Students with visual impairments have been receiving school education services from 
sixteen integrated schools across the country (Ministry of Education, 2017). Integrated schools refer to those schools where general education teachers teach to all students with and without disabilities together in general classrooms, and special education teachers provide additional academic supports especially in content areas for visually impaired students in resource rooms to boost their learning. Integration focuses mainly on physical and social access with limited or no academic expectations for students with severe disabilities (Villa \& Thousand, 2016). The sighted and the students with visual impairments have to get mastery of the same content areas of learning (Farrell, 2017) in integrated schools. Even though students with visual impairments study the same curriculum as their sighted peers in integrated educational settings, their learning needs and styles are hugely different from their peers without disabilities. The learning needs of visually impaired students may be different from each other, even having similar types of disability (Vaughn, Bos, \& Schumm, 2018). These students, therefore, cannot get ample benefits from conventional instructional techniques as compared to their typically developing peers.

Children with visual impairment are ranged from low vision to complete blindness (Mastropieri \& Scruggs, 2018; Heward, 2013). Nearly, $75 \%$ to $80 \%$ of school-age visually impaired children have some potentially useful vision (Lewis \& Tolla, 2003). However, blind learners cannot receive important information through their sense of vision and they have to rely on their tactile and auditory senses to obtained relevant information from the external world. Functionally blind students can use their limited vision to supplement the information obtained from the other senses (Vaughn et al., 2018; Kirk, Gallagher, \& Coleman, 2015; Heward, 2013). However, students with low vision can use their visual sense as a primary avenue of learning (Heward, 2013; Kirk, Gallagher, Coleman, \& Anastasiow, 2012). Many students with visual impairments have to learn different curricular content by using other senses, mainly touch and hearing (Friend, 2011). In this regard, valid and significant instructional modes should be employed to ensure these children's access to curricular contents to an optimum level.

Two students studying at a class learn specific curricular content in different paces despite encountering similar learning environment. Some students can learn curricular content quickly as compared to their classmates, and some of them may require more time to make a clear concept on content suggested from the specific subject area. Generally, gifted and talented students learn any content more quickly as compared to their peers without disabilities. Many of them learn prescribed content within one-third of the time that average learners need (Kirk, Gallagher, \& Coleman, 2015; Heacox, 2002). They require fewer examples, little explanation, and shorter practice time but students with disabilities, including those with visual impairments, may require more time to get mastery of a similar content domain. Visual problem of an individual not only impacts on his/her learning but also affect different aspects of his/her life. The cognitive and expressive aspects of processing information are likely to be significantly impacted by a lack of visual input (Kirk et al., 2015; Allman \& Lewis, 2014) that cause poor access to the curriculum. Consequently, students with visual impairments need more instruction, examples, practice time, and feedback to get success (Gargiulo \& Metcalf, 2013; Heacox, 2002) under the formal education system. Therefore, teachers teaching to children with visual impairments should practice those instructional approaches that are suited to them based on their peculiar learning needs and styles to maximize their access to the school curriculum. 
Students with visual impairments require braille and large-print textbooks, assistive technology, double time in the exam to blind, 50\% additional time to students with low vision (Vaughn et al., 2018) to have proper access to curricular contents. Assistive technologies such as screen magnifier software, video magnifiers, screen reader software, scanners, braille displays, braille notetakers, and the like are also beneficial to visually impaired students to optimize their access to the curriculum (Salisbury, 2008). These students can also be benefited from cooperative instructional techniques (Mastropieri \& Scruggs, 2018; Villa \& Thousand, 2016). These instructional techniques, therefore, should be applied by acknowledging their unique learning needs and styles to make them successful in their academic careers to a fuller extent possible. But studies (Human Rights Watch, 2018; Jung \& Niure, 2018 for example) have revealed that almost all the teachers teaching in integrated schools do not have proper knowledge about the distinct needs of learners, Individualized Education Plan, cooperative instructional techniques, differentiated instruction, and assessment accommodations. A number of children with disabilities, including those with visual impairments, quit their school in earlier grades because of poor instructional delivery (Human Rights Watch, 2011), limited physical facilities, lack of proper support (Jung \& Niure, 2017; Regmi, 2017), and lack of instructional materials prepared in braille (Human Rights Watch, 2011). Furthermore, the instructional techniques used in the class are not interactive, participatory, and meaningful to the learners (Curriculum Development Center, 2007). Teachers teaching to students with visual impairments usually use traditional instructional approaches instead of using project-based assignments and student-centered activities (Morris, 2014). A significant number of teachers feel overwhelmed and unprepared to cope with the situation due to inadequate knowledge about diverse instructional strategies (Oliver, 2016). Consequently, these students face difficulty in concentration, orientation and mobility, and learning (Agesa, 2014). In this regard, this study was carried out to explore the instructional strategies that have been applying by integrated school teachers to cater the special learning needs of students with visual impairments by ensuring their access to the official curricula. This research, therefore, will be helpful to all people and agencies (GOs, NGOs, and INGOs) working in the field of special/special needs/inclusive education to provide relevant educational services for all learners including those with visual impairments either in general, special, or integrated educational settings.

\section{Objective and Research Question}

The purpose of this study is to explore the instructional approaches that have been using by teachers working in integrated schools for years to optimize the access of visually impaired students to general education curriculum. A research question - What types of instructional techniques have been using by teachers by targeting the special learning needs of students with visual impairments in integrated schools? - has been answered to achieve this objective.

\section{Research Methodology}

This study was guided by constructivist paradigm followed by case study design (Creswell \& Poth, 2018; Yin, 2018; Terrell, 2016). Eleven teachers (five special and six general education teachers) were selected from three integrated schools located in Kathmandu Valley by using purposive sampling method where a significant number of students with visual impairments were receiving educational services alongside their sighted peers. All of these sample teachers were interviewed 
individually by following a semi-structured interview guideline to collate in-depth information regarding instructional techniques that have been using by them to cater peculiar learning needs of students with visual impairments. Six classrooms (two from each sample school) were also visited to observe the instructional techniques used in both resource rooms and general education classroom and then related documents were also reviewed to get deeper understanding on the problem that was proposed under this study. And then garnered information was analyzed in a descriptive way by generating some themes to answer the research question. It means; all of the data gleaned from multiple sources were edited, transcribed, coded, and thematized to draw meaningful results and conclusions based on the research question. Different techniques namely triangulation, rich description, and peer review (Merriam \& Tisdell, 2016; Creswell, 2015) were also used to ensure the reliability and validity of this article.

\section{Results}

All students who enrolled in a particular class cannot get similar benefits from common content delivery modes because of their individualized learning profiles (Mastropieri \& Scruggs, 2018; Heward, 2013). The instructional techniques generally useful to sighted students may not be beneficial to the students with visual impairments to a similar extent (Allman \& Lewis, 2014). Since the students studying in an integrated classroom are hugely dissimilar from each other, the teachers working there should use a wide range of instructional modes while teaching specific curricular contents. Interactive and activity-based instructional modes (discussion, experimental, project, for example) are more useful to offer active participation of learners as compared to conventional instructional techniques (lecture, demonstration, for example). Study results revealed that a number of instructional modes were applying by teachers in integrated classrooms to deliver curricular contents. Nevertheless, these instructional techniques were not practiced in all integrated schools to a similar degree of intensity. Some of these instructional techniques were used on routine basis but some of them were not applied regularly. The instructional modes applied by targeting the peculiar learning needs of the students with visual impairments are given below correspondingly:

Providing Braille, large-print, and audio materials: Students with visual impairments need a range of instructional materials to maximize their access to the general education curriculum to a fuller extent. Students with low vision and blindness cannot access normally printed textbooks and other useful materials. Blind students can get ample benefits from the materials that are prepared in braille and audio versions, but students with low-vision can also be benefitted from large-print materials, General Education Teacher-2 from School-C said. Blind and students with low vision have been taking tremendous benefits Braille and large-print textbooks respectively, Special Education Teacher-1 from School-B replied. But classroom observation revealed that even though textbooks were distributed to visually impaired students in accessible format, they could not get access to other supplementary materials as their sighted peers to optimize their access to curricular contents.

Communicating written contents through oral mode: Some students with visual impairments can only receive information through audio and tactile modes. Therefore, teachers teaching to these students should convey specific instructions and questions through oral mode to make 
them accessible. Most of the teachers participated in the research process concurred that they usually spoke loudly while writing particular contents on the chalkboard mainly to make the information accessible to all learners including those with visual impairments. I read everything loudly that I write on the chalkboard by considering the learning needs of blind students, General Education Teacher-2 from School-A replied. Classroom observations also showed that some teachers were providing oral instruction and speaking loudly while writing on the chalkboard. $A$ teacher wrote some rules of Nepali grammar on the chalkboard and communicated all written contents orally. Students with visual impairments also recorded some crucial points told by the teacher in Braille [Observation of Class-1 from School-A]. Thus, most of the contents delivered in the classroom were communicated through oral mode to make them accessible to students with visual impairments.

Allocating more time to read curricular contents: Visually impaired students cannot read normal-print as their typically developing peers can. These students, therefore, require textbooks and other reading materials printed in Braille. Though these students receive curricular contents prepared either in Braille or large-print version, they cannot read the contents at the same pace as their sighted peers. These students, therefore, need extended time to get mastery of the lesson taught in the classroom. Study results also revealed that more time was allocated to these students by acknowledging their peculiar learning needs and styles. Each student with visual impairments is allowed to read contents from textbooks in his/her own pace, General Education Teacher-2 from School-B replied. Supporting the argument, another teacher said, additional time is given to visually impaired students to read the text written either in Braille or large print [General Education Teacher-1 from School-C]. But classroom observations showed that no reading activities were carried out during instructional time except one classroom where only sighted students studied specified contents within stipulated time bound. Nevertheless, responses given by sample teachers depicted that additional time was given to them while conducting reading activities inside the classroom to allow them to proceed based on their own pace.

Delivering important information through lecture mode: Almost all teachers participated in the research process informed that lecture method is very beneficial to students with visual impairments. Consequently, all sample teachers were using this method as a core instructional technique to convey curricular contents especially from language and social science subjects, Nepali and social studies for examples. Blind students can easily comprehend all subject matter delivered by using lecture method, General Education Teacher-2 from School-A answered. Lecture method is more effective than other methods to convey theoretical contents to visually impaired students, Special Education Teacher-1 from School-B said. Classroom observations also showed that most of the lessons were mainly dominated by lecture mode, but the questionanswer mode was also used as a supplementary technique in most of the observed classrooms.

Placing visually impaired students near to chalkboard: Study results showed that almost all students with low vision were placed near to chalkboard primarily to optimize their access to information written there. In most of the cases, blind students were also placed with a typically developing student by making a pair between them and later one provided different types of academic supports to earlier one. Each visually impaired student was paired with a sighted student 
and placed them in the first and second benches of the class to make the school curriculum more accessible, General Education Teacher-2 from School-A stated. Sighted students not only provide academic supports to blind peers but also help them manage their stationaries and execute other daily living activities, General Education Teacher-2 from School-C informed. Classroom observation also showed that blind students were seated with their sighted peers in the first row of the class, and sometimes, students with visual impairments were supported by their sighted peers to solve the problems posed by their subject teachers.

Using abacus, manipulative, and tactile materials: A significant number of teachers teaching to visually impaired students were using abacus, manipulative, and tactile materials to convey mathematical contents clearly particularly in lower grades. We usually use abacus and some useful tactile materials to clarify mathematical contents recommended within the curriculum, Special Education Teacher-2 from School-B said. Abacus is very useful tool to teach addition, subtraction, multiplication, and division to visually impaired students; therefore, we use it regularly in resource room to convey basic mathematical concept encompassed within the curriculum, Special Education Teacher-1 from School-C indicated. Thus, different instructional materials were used by considering the special learning styles of students with visual impairments. Nevertheless, study results showed that these materials were not applied on routine basis except some sample schools involved in the research process.

Ability based grouping: Students with visual impairments are differently abled than their peers with normal vision. Considering the reason, all integrated schools were composing different groups based on their learning ability and then educational supports were provided to visually impaired students through pull out services by acknowledging their peculiar needs and learning styles. Students with visual impairments cannot meet their unique learning needs in the general classroom; therefore, special education supports are provided to them especially in resource room to ensure their access to the general education curriculum, Special Education Teacher-1 from School-C answered. Furthermore, another teacher said, it is so easy to teach homogeneous group as compared to heterogeneous group...since students with visual impairments are significantly different than students without disabilities..., they are taught separately in resource rooms for additional academic supports [General Education Teacher-2 from School-C]. However, classroom observations depicted that almost all special teachers working in integrated schools were investing most of their time and energy for developing braille competency of visually impaired students rather providing supports in curricular contents.

Pairing students: Most of the teachers participated in the study expressed that pair grouping was found more useful and productive to increase the access of visually impaired students to the general education curricula. In pair grouping, each pair was composed of a visually impaired student and a student without disabilities, and then each of them was asked to sit together in a desk primarily to support visually impaired one, General Education Teacher-2 from School-A informed. Generally, sighted students worked as a facilitator to clarify curricular content and describe questions posed by subject teachers to make them more accessible to their visually impaired peers. In this regard, a teacher stated that each student with visual impairments is paired with an academically sound student in the class to provide academic support to a special one 
Content Delivery Modes for Students with Visual Impairments in Integrated Schools... / 63

[Special Education Teacher-2 from School-B]. A sighted student also assists in clarifying and handling different types of questions asked by subject teachers as a part of classwork, homework, or unit test, General Education Teacher-1 from School-A clarified. Thus, the groups made by pairing both sighted and visually impaired students were found beneficial to students with visual impairments not only for an instructional purpose but also for assessment purpose.

\section{Discussion}

Since educational needs, preferences, and learning styles of students with visual impairments are significantly different from their sighted peers, they cannot get ample benefits from the instructional modes that are primarily applied for the students without disabilities (Tomlinson, 2017). Blind students can be benefitted from audio materials, Braille textbooks, and readers, but students with low vision can also be profited by videotape, magnifying devices, large-print materials (Hallahan, Kauffman, \& Pullen, 2012; Palmer, 2005), audiotape, computer (Kirk et al., 2015; Heward, 2013), and the like. Study results showed that textbooks in braille and largeprint versions have been provided to all students with blindness and low vision in all integrated schools of Nepal to make the knowledge, values, and skills encompassed within a curriculum more accessible. But other instructional materials except textbooks had not been provided in Braille and large-print formats. Consequently, most of these children were compelled to be fitted into those instructional materials which were offered merely by considering learning styles of sighted students. Though many students with visual impairments use audio mode as a simple and effective medium for accessing information, materials containing diagrams and tables may be difficult to explain in audio format (Salisbury, 2008). In this regard, teachers can use descriptive language to provide a clear picture of an event and tell information written on the chalkboard loudly (Lewis \& Doorlag, 2011) to make them accessible. The study results also revealed that some integrated schools of Nepal have been providing an audio version of the text to visually impaired students to maximize their access to subject matters. Almost all general education teachers claimed that they also read most of the text written on the chalkboard loudly to make them comprehendible for visually impaired students.

Different instructional materials such as three-dimensional circles of wood and abacus are beneficial to teach fundamental mathematical concepts (number, addition, substation, fractions, for example) to visually impaired students (Kirk et al., 2012; Lewis \& Tolla, 2003). Besides, character recognition software is also helpful to convert printed or electronic text into spoken words for these students (Lewis \& Tolla, 2003). Hands-on experiences are also necessary to develop the skills of handling money, weighing, measuring, exploring geometrical shapes, and making fractional parts (Farrell, 2017). In this regard, study results showed that only limited assistive devices (abacus, tactile materials, for example) were applied in all integrated schools. A significant number of teachers working in integrated classrooms were using conventional instructional techniques without manipulating sufficient assistive technologies based on the distinct learning needs of blind students (Morris, 2014) that had minimized their access to the official curricula. Teachers neither mobilize available resources nor apply practical instructional techniques to develop intended behavior of learners with visual impairment due to inadequate training (Sikanku, 2018; Nimmo, 2008). Consequently, most of the teachers are still puzzled about the ways that need to be followed to accommodate instructional techniques based on special 
learning needs of these learners (Oliver, 2016). Constructivists argue that semiotic mediation plays a crucial role in constructing knowledge. Hence, semiotic means language, various systems of counting, mnemonic techniques, sign language, writing, diagrams, maps, etc. (Bozkurt, 2017; John-Steiner, Connery, \& Marjanovic-Shane, 2010). The internalization of semiotics helps a learner in the knowledge construction process (Bozkurt, 2017). Braille is taken as a semiotic useful to visually impaired students to have access to information included within a curriculum. Braille, therefore, had been taught to students with visual impairments in all integrated schools, especially in resource rooms, by special teachers. Constructivists also believe that an effective teaching always offers instructional materials based on students' learning level (Wang, 2009). Considering the fact, different types of instructional materials (braille and large-print textbooks, abacus, for example) had been provided to visually impaired students to meet their peculiar learning needs under an integrated educational setting in Nepal. Lecture mode was also used as a core technique to deliver curricular contents to the students with visual impairments.

Co-teaching techniques are very useful to teach students with and without disabilities together (Gargiulo \& Metcalf, 2013) under an integrated educational setting. In cooperative teaching practices, both general and special teachers work collaboratively in planning and delivering instruction (Villa \& Thousand, 2016; Heward, 2013). They blend whole-class, small-group, and individual instruction on a required basis. Both teachers and students work together and try to learn something from each other (Tomlinson, 2017). Pairing students to master textual material, working with students individually or in small groups, and creating interactive environment within a class by considering diversified learning needs of students are some examples of cooperative instructional techniques that can be used to adapt instructional process (Polloway, Patton, \& Serna, 2008) based on peculiar needs and learning styles of students including those with visual impairments. But the study results depicted that although some cooperative instructional techniques (pairing students, grouping based on the ability, for example) are practiced in some integrated schools, these attempts are not enough to enable visually impaired students to learn curricular content to a fuller extent possible. In this regard, constructivists accept classrooms as social entities where students, who come from diverse backgrounds, interact with each other to construct knowledge (Ornstein \& Hunkins, 2017; Pritchard \& Woollard, 2010). Learners usually learn specific content effectively through interaction (Bozkurt, 2017; Akpan \& Beard, 2016; Hussain, 2012; Wang, 2009), cooperative learning, and problem-based learning (Akpan \& Beard, 2016; Gargiulo \& Metcalf, 2013; Hussain, 2012) than other instructional strategies. Each learner has to do some actions to learn particular content validly. Nevertheless, all students neither have a similar learning pace nor get mastery of specific content within the same amount of time even performing similar types of activities under a particular learning condition. Curricular content, therefore, should be delivered by considering the peculiar learning pace of learners, including those with visual impairments, to enhance their access to the curriculum to a maximum level. In this regard, study results show that special learning needs and styles of students with visual impairments have not been adequately recognized in integrated schools of Nepal as indicated by other studies (Human Rights Watch, 2011 for example). Most of the teachers prefer teaching sighted students as compared to visually impaired students evening working in an inclusive educational setting (Sikanku, 2018). Consequently, they had poor access to the curriculum as compared to their peers without disabilities under an integrated educational setting. 
Since students with visual impairments read curricular content slowly as compared to their sighted peers, some of them may need extra time to locate content in their textbooks, find starting place, and complete classroom activities assigned to them (Lewis \& Doorlag, 2011). They require $50 \%$ to $100 \%$ more time to complete some assignments (Lewis \& Doorlag, 2011; Gompel, Van Bon, \& Schreuder, 2004) from the general education curriculum. The additional time provided by subject teachers to explore and ask questions about their curiosity can be helpful for them (Vaughn et al., 2018) to have access to curricular content as students without disabilities. In this context, study results showed that sufficient time had not been provided to visually impaired students by acknowledging their distinct learning needs and styles either while carrying out instructional activities in the classrooms or conducting different types of exams. Furthermore, alternative acquisition modes (audio tape, braille, for example) and alternative response modes (oral responding, untimed responding, for example) are also used while accommodating particular tests or exams (Polloway et al., 2008). However, the accommodations made for one student with visual impairments may not be relevant to another student with the same disability (Venn, 2007). A blind student can get benefit from braille or a cassette version of a test, a reader, and a writer, but a student with low vision requires large-print questions rather than a braille version of a test. By considering the peculiar learning needs of students with visual impairments, assessment procedures, to a moderate extent, have been accommodated in Nepalese integrated schools to make them accessible.

\section{Conclusions}

Since educational needs, learning pace, and learning styles of students with visual impairments are significantly different than their peers without disabilities, they cannot get ample benefits from the general instructional techniques that are suited to sighted students. Although students with visual impairments study general education curricula with their sighted peers under an integrated educational setting, they should be taught by applying special instructional modes that are suited to them. Accounting the fact, different content delivery modes have been using to deliver prescribed subject matter to visually impaired students in all integrated schools. Nevertheless, these instructional techniques have not been practiced on routine basis because of poorly trained teachers, limited assistive devices, high students-teacher ratio, and over-loaded course. Teachers either general or special, teaching under an integrated educational setting, were sharply bounded by inflexible curricula, rigid physical infrastructure, structured schedule, and textbooks. Therefore, proper training, sufficient assistive devices, manageable class size, and relevant course should be arranged to maximize the access of visually impaired students to curricular contents.

\section{Implications}

Content delivery modes are taken as an important part of educational program to make the teaching learning process more effective by considering the individual learning needs of students including those with visual impairments. All of the resources, time, and efforts go in vain in the absence of responsive instructional techniques. This study, therefore, will be beneficial to select and implement relevant and valid instructional techniques especially for students with visual impairments to optimize their academic achievement to a maximum level. This research, therefore, will be helpful to all teachers, either general or special, working with visually impaired 
students to design functional school policies, productive educational programs, relevant curricula, select appropriate instructional materials, valid learning experiences, and authentic evaluation techniques to maximize the learning of all learners studying either in general, special, or integrated educational settings. For long term, this study will also be handy to meet the legal mandates of the government and implement democratic values by making instructional activities more accessible to all learners including those with visual impairments.

\section{References}

Agesa, L. (2014) Challenges faced by learners with visual impairments in inclusive setting in Trans-Nzoia County. Journal of Education and P ractice, 5 (29), 185-192. ISSN 22221735 .

Akpan, J. P., \& Beard, L. A. (2016). Using constructivist teaching strategies to enhance academic outcomes of students with special needs. Universal Journal of Educational Research 4(2), 392-398. DOI: 10.13189/ujer.2016.040211.

Allman, C. B., \& Lewis, S. (2014). ECC essential: Teaching the expanded core curriculum to students with visual impairments. USA: AFB Press, American Foundation for the Blind.

Bozkurt, G. (2017). Social constructivism: Does it succeed in reconciling individual cognition with social teaching and learning practices in mathematics? Journal of Education and Practice, 8(3), 210-218. ISSN 2222-1735.

Creswell, J. W. (2015). Educational research: Planning, conducting, and evaluating quantitative and qualitative research (4th edition). USA: Pearson Education Inc.

Creswell, J. W., \& Poth, C. N. (2018). Qualitative inquiry and research design: Choosing among five approaches (4th edition). USA: SAGE Publications.

Curriculum Development Center (2007). National curriculum framework. Bhaktapur, Sanothimi: Author.

Farrell, M. (2017). Educating special students: An introduction to provision for learners with disabilities and disorders (3rd edition). London: Routledge, Tyler and Francis Group.

Friend, M. (2011). Special education: Contemporary perspectives for school professional (3rd edition). New Jersey: Pearson Education, Inc.

Gargiulo, R. M., \& Metcalf, D. (2013). Teaching in today's inclusive classrooms (2nd edition). USA: Wadsworth, Cengage Learning.

Gompel, M., Van Bon, W. J. J., \& Schreuder, R. (2004). Reading by children with low vision. Journal of Visual Impairments and Blindness, 98, 77-89.

Hallahan, D. P., Kauffman, J. M., \& Pullen, P. C. (2012). Exceptional learners: An introduction to special education (10th edition). New Jersey: Pearson Education, Inc.

Heacox, D. (2002). Differentiating instruction in the regular classroom: How to reach and teach all learners, grade 3-12. USA: Free Spirit Publishing Inc. 
Content Delivery Modes for Students with Visual Impairments in Integrated Schools... / 67

Heward, W. L. (2013). Exceptional children: An introduction to special education (10th edition). USA: Pearson Education, Inc.

Human Rights Watch (2011). Future stolen: Barriers to education for children with disabilities. Retrieved from https://reliefweb.int/report/nepal/futures-stolen-barrierseducationchildren disab-ilities-nepal.

Human Rights Watch (2018). Barriers to inclusive education: Segregation, lack of accessibility for children with disabilities. Retrieved from https://www.hrw.org/news/2018/ 09/13/ nepal-barriers-inclusive-education.

Hussain, I. (2012). Use of constructivist approach in higher education: An instructors' observation. Creative Education, 3(2), 179-184.

John-Steiner, V.; Connery, M. C., \& Marjanovic-Shane, A. (2010). Dancing with the muses: A cultural-historical approach to play, meaning making and creativity. In M. C. Cannery, V. P. John-Steiner, and A. Marjanovic-Shane (editors). Vygotsky and Creativity: A Cultural-historical Approach to Play, Meaning Making, and the Arts. New York: Peter Lang Publishing, Inc.

Jung, D. Y., \& Niure, D. P. (2017). Barriers to inclusive education in Nepal. Korean Journal of Special Education, 52(2), 1-18. DOI: http://dx.doi.org/10.15861/ kjse. 2017.52.2.1

Jung, D. Y., \& Niure, D. P. (2018). Differentiated instruction for addressing the learning needs of children with disabilities: Reality and challenges in Nepalese special and integrated schools. Korean Journal of Special Education, 53(1), 83-103. DOI:http://dx.doi.org/ 10.15861/kjse. 2018.53.1.83

Kirk, S., Gallagher, J., \& Coleman, M. R. (2015). Educating exceptional children (14th edition). USA: Cengage Learning.

Kirk, S., Gallagher, J., Coleman, M. R., \& Anastasiow, N. (2012). Educating exceptional children (13th edition). USA: Wadsworth, Cengage Learning.

Lewis, R. B., \& Doorlag, D. H. (2011). Teaching students with special needs in general education classroom (8th edition). New Jersey: Pearson Education, Inc.

Lewis, S., \& Tolla, J. (2003). Creating and using tactile experience books for young children with visual impairments. Teaching Exceptional Children, 35(3), 22-28.

Mastropieri, M. A., \& Scruggs, T. E. (2018). The inclusive classroom: Strategies for effective differentiated instruction (6th edition). USA: Pearson Education, Inc.

Merriam, S. B., \& Tisdell, E. J. (2016). Qualitative research: A guide to design and implementation (4th edition). USA: John Wiley \& Sons, Inc.

Ministry of Education (2017). Inclusive education policy for the persons with disabilities - 2017. Kathmandu: Author.

Morris, C. (2014). Seeing sense: The effectiveness of inclusive education for visually impaired students in further education. School of Social Sciences, Cardiff University. Retrieved from https://orca.cf.ac.uk/69396/1/Final\%20Version\%20Thesis\%20\%20Ceri \%20 Morris.pdf 
Nepal Law Commission (2015). The constitution of Nepal. Retrieved from http://www. lawcommission.gov.np/en/documents/2016/01/ constitution-of-nepal-2.pdf

Nimmo, S. (2008). Examining the factors of successful inclusion of students with vision impairment. Coursework project in Special Education, Flinders University. Retrieved from http://www.flinders.edu.au/ehl/fms/projects_files/5_2008.pdf

Oliver, F. E. (2016). Teachers'perspectives on differentiated instruction in the foreign language classroom. Faculty of Teacher Education, School of Education, University of Iceland. Retrieved from https://skemman.is/bitstream/1946/26468/2/Fiona_Oliver.pdf

Ornstein, A. C., \& Hunkins, F. P. (2017). Curriculum: Foundations, principles, and issues (7th edition). New York: Person Education, Inc.

Palmer, C. (2005). Educating learners with vision impairment in inclusive settings. International Congress Series 1282, 922-926. DOI:10.1016/j.ics.2005.05.132

Polloway, E., Patton, J. R., \& Serna, L. (2008). Strategies for teaching learners with special needs (9th edition). New Jersey: Pearson Merrill Prentice Hall.

Pritchard, A., \& Woollard, J. (2010). Psychology for the classroom: Constructivism and social learning. London: Routledge, Tyler and Francis Group.

Salisbury, R. (2008). Teaching pupils with visual impairment: A guide to making the school curriculum accessible. London: Routledge Tyler and Francis Group.

Sikanku, S. T. (2018). Challenges in teaching pupils with visual impairment in inclusive classrooms: The experience of Ghanaian teachers. Research on Humanities and Social Sciences, 8 (11), 4348. ISSN 2224-5766.

Terrell, S. R. (2016). Writing a proposal for your dissertation: Guidelines and examples. London: The Guilford Press.

Tomlinson, C. A. (2017). How to differentiate instruction in academically diverse classrooms (3rd edition). USA: Association for Supervision and Curriculum Development.

Vaughn, S. R., Bos, C. S., \& Schumm, J. S. (2018). Teaching students who are exceptional, diverse, and at risk in the general education classroom (7th edition). USA: Pearson Education, Inc.

Venn, J. J. (2007). Assessing students with special needs (4th edition). New Jersey: Pearson Education, Inc.

Villa, R. A., \& Thousand, J. S. (2016). The inclusive education checklist: A self-assessment of best practices. USA: Dude publishing, A Division of National Professional Resources, Inc.

Wang, Y. (2009). Impact of Lev Vygotsky on special education. Canadian Social Science, 5(5). ISSN 1712-8056, 100-103.

Yin, R. K. (2018). Case study research and application: Design and methods (6th edition). London: SAGE Publications, Inc. 